\title{
An Improved Ultrasound-Assisted Extraction Process of Gossypol Acetic Acid From Cottonseed Soapstock
}

\author{
Guangfeng Jia \\ Key Laboratory of Biomedical Information Engineering of Education Ministry, \\ School of Life Science and Technology, Xi'an Jiaotong University, Xi'an 710049, China; \\ Institute of Natural Product Chemistry, Dept. of Chemistry, Shaanxi Institute of Education, Xi'an 710061, China \\ Yonghua Zhan and Daocheng Wu \\ Key Laboratory of Biomedical Information Engineering of Education Ministry, \\ School of Life Science and Technology, Xi'an Jiaotong University, Xi'an 710049, China \\ Yang Meng and Liang $\mathrm{Xu}$ \\ Dept. of Radiation Oncology, Div. of Cancer Biology, University of Michigan, Ann Arbor, Michigan, MI 48103
}

DOI 10.1002/aic.11700

Published online January 22, 2009 in Wiley InterScience (www.interscience.wiley.com).

\begin{abstract}
To investigate the extracted process of gossypol acetic acid $(G-A A)$ from cottonseed soapstock and explore the improvement of its yield and purity, a novel ultrasoundassisted extraction and crystallization method was introduced to this process. Under the optimized conditions, preliminary G-AA with the yield of $1300 \mathrm{mg}$ and the purity of $95.9 \%$ could be obtained from $100 \mathrm{~g}$ of fresh soapstock by ultrasound-assisted extraction. In addition, $U V, I R$, and NMR spectrum further confirmed the detailed chemical structure of G-AA. Assay of inhibiting human prostate tumor cell line PC-3 and human breast cancer cell line MDA-MB-231 revealed its biological activity, the values of $I C_{50}$ are $9.096 \mu \mathrm{mol} / \mathrm{L}$ and $14.37 \mu \mathrm{mol} / \mathrm{L}$ respectively. In comparison with the conventional solvent extraction, this novel process increases the content of $G-A A$ over $90 \%$, reduces the time of crystallization by $75 \%$, and retains the anticancer activity of gossypol. @ 2009 American Institute of Chemical Engineers AIChE J, 55: 797-806, 2009 Keywords: ultrasound, soapstock, gossypol, gossypol acetic acid, anticancer
\end{abstract}

\section{Introduction}

Gossypol is a yellow polyphenolic compound found in pigment glands distributed throughout the cotton plant (Gossypium sp.), which has been associated with a wide range of biological and medicinal activities, including antifertility, ${ }^{1}$ antimalarial, ${ }^{2}$ antitumor, ${ }^{3}$ and antiviral ${ }^{4}$ effects. Therefore, it is widely used in medical and pharmaceutical field. Recently, some bio-medical research ${ }^{5-11}$ suggested that gossypol is a

Correspondence concerning this article should be addressed to D. Wu at wudaocheng@mail.xjtu.edu.cn.

(C) 2009 American Institute of Chemical Engineers promising novel anticancer drug. Gossypol has two enantiomers. Benz et al. ${ }^{12}$ found correlation of the antitumor and antimitochondrial properties of gossypol enantiomers, and believed that the antimitochondrial effect of (-)-gossypol correlated with its antiproliferative activity. It was also noted that (-)-gossypol modified the resistance of human carcinoma cells to other chemotherapeutic agents because of the increase in glutathione-S-transferase and protein kinase $\mathrm{C}$ content. Oliver et al. $^{13}$ reported that (-)-gossypol acted directly on mitochondria to overcome the antiapoptotic function of Bcl-2 and Bcl-xL. Our previous report ${ }^{14}$ showed that (-)-gossypol inhibited the antiapoptotic proteins $\mathrm{Bcl}-2 / \mathrm{Bcl}-\mathrm{xL}$ and radiosensitized prostate cancer cells in vitro and in vivo without augmenting toxicity. Currently, (-)-gossypol has 


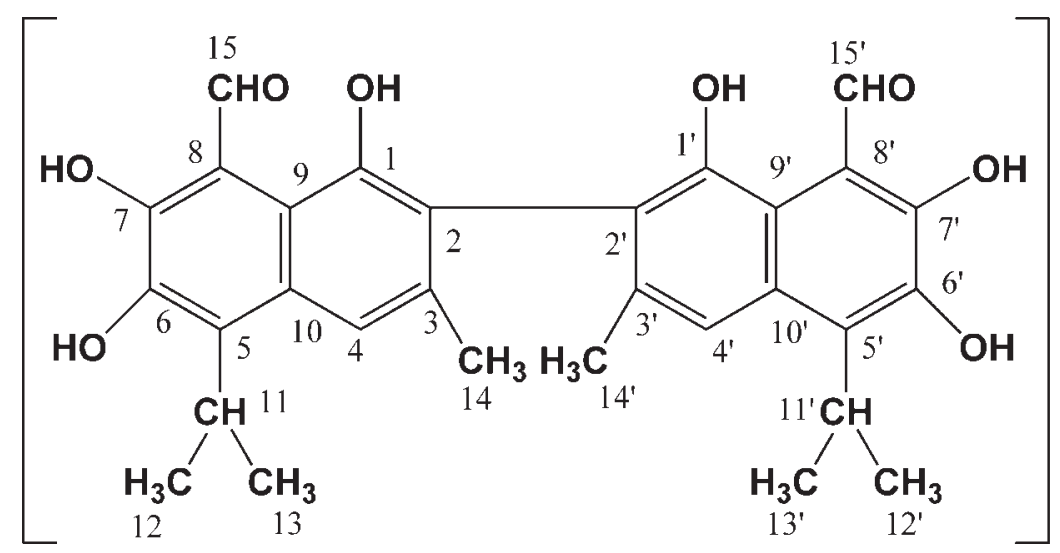

\section{$\mathrm{CH}_{3} \mathrm{COOH}$}

$16 \quad 17$

Figure 1. Chemical structure of G-AA.

shown promising results in Phase I clinical trial for cancer therapy and is now in Phase II clinical trial in the USA. With more and more biological and clinical investigation on gossypol, the demand for large amounts of pure and pharmacologically active gossypol will greatly increase. However, because gossypol was prone to be oxydized in air, it was usually turned into stable gossypol acetic acid (G-AA) (Figure 1) with glacial acetic acid during production.

To meet the growing demand for the medicinally active gossypol in pharmaceutical industry, several methods for extracting gossypol were developed. The initial preparations of gossypol employed cottonseed or defatted cottonseed, ${ }^{15}$ the root bark of the cotton plant, ${ }^{16}$ or isolated pigment glands. ${ }^{17}$ However, there were at least two severe shortcomings in these procedures. One is that the products are quite expensive and crude because of the low content of gossypol in raw materials and the high consumption of extracting solvent. The other is that these methods will lead to a potential risk in food and feedstuff safety due to some toxic organic extracting solvents remained in oil and protein. Therefore, it is important to develop a safer process for preparing large amounts of high purity gossypol with economical material.

Soapstock, the byproduct of alkali refining cottonseed oil, was developed as the substitute material for producing gossypol. It used to be thrown away as rubbish because of its ugly color and rotten odor, which results in severe atmosphere pollution. However, it was reported that gossypol in bound state is enriched at $2-8 \%$ in soapstock. ${ }^{18}$ It is clear that soapstock maybe a proper material for the recovery of gossypol, and this process will make for relieving environmental contamination in the refining oil factories. Dowd et al. ${ }^{18}$ proposed a conventional solvent extraction procedure to produce large amounts of research-grade gossypol by cottonseed soapstock. Despite their success in recovery of gossypol from cottonseed soapstock in lab, it is unclear whether their product had antitumor effect, and no tested data have been reported, and there are several puzzles in its industrialization, such as low purity, long producing cycle and complicated processing program.

Ultrasound-assisted extraction uses acoustic cavitations to cause molecular movement of solvent and samples, which offers advantages of improved efficiency, reduced extraction time, low solvent consumption and higher level of automation compared with conventional extraction techniques. ${ }^{19}$ Consequently, the increasing use of ultrasound extraction has been investigated in the pharmaceutical, chemical and food industries. This is a well-established method in the processing of plant material, especially in extraction of low molecular weight substances, ${ }^{20}$ and of bioactive substances from plants. ${ }^{21}$

Sonocrystallization is the use of power ultrasound to control the crystallization process. Power ultrasound was used principally to affect the initial nucleation stage of crystallization, that is, the width of the metastable zone is reduced and nucleation starts at a lower level of supersaturation. ${ }^{22-24}$ The utilization of ultrasound to crystallization in the pharmaceutical and fine chemicals industry has received further impetus in recent years. The corresponding equipments to prepare and purify complex chemical entities to different exacting standards ${ }^{25}$ have been designed and applied. Therefore, ultrasonic crystallization has become a relative mature technique in the pharmaceutical and fine chemicals industry.

To improve the gossypol extraction procedure from soapstock, we have developed an improved process for recovering large amount, pure and active G-AA from cottonseed soapstock by the powerful ultrasound assisted extraction and crystallization technology. The yield of crude product reached at $1.3 \mathrm{~g}$ and the content of G-AA was $95.9 \%$ in the initial extracts. Our product has the same chemical structure with standard sample according to UV, IR, and H NMR spectrums. Primary biological test revealed that our product showed excellent antitumor activity. Hence, this novel process of ultrasound assisted extraction and crystallization may be adopted in preparing the large scale G-AA from cottonseed soapstock, and G-AA may have promising biomedical use in the future.

\section{Materials and Methods \\ Materials preparation and handling}

Soapstock from a local miscelle-refining cottonseed oil mill (Shannxi Shiyang, China) was collected immediately after centrifuge and was rapidly stored in the $-20^{\circ} \mathrm{C}$ refrigerator. G-AA standard was offered by National Institute for the 


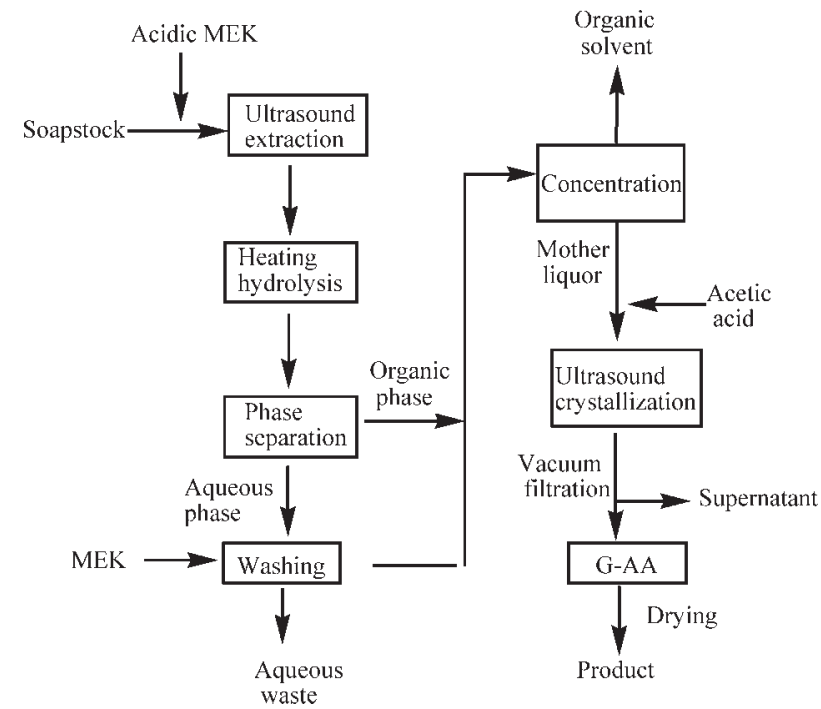

Figure 2. Process schematic of the recovery of G-AA from cottonseed soapstock by ultrasound.

Control of Pharmaceutical and Biological Products in China. All the chemical reagents were of analytical grade.

Soapstock gossypol concentration was determined by the American Oil Chemists' Society Official Method. ${ }^{26}$ alkali concentration was estimated by dispersing $1.0 \mathrm{~g}$ of soapstock in $30 \mathrm{~mL}$ of deionized water and measuring $\mathrm{pH}$. We used the soapstock containing $2 \%$ gossypol (calculated by G-AA) and $\mathrm{pH} 8.0$ in this study.

\section{Recovery process}

On the basis of a method described by Down et al., ${ }^{18}$ we proposed a modified procedure (Figure 2) which includes extracting gossypol from soapstock with ultrasound water bath, hydrolyzing bound gossypol in acid condition, partitioning the gossypol into an organic phase and gathering all extract, concentrating the combined gossypol solution by vacuum distillation, and crystallization by power ultrasound. Briefly, $(100 \pm 1) \mathrm{g}$ of soapstock was dispersed in $100 \mathrm{~mL}$ of methyl ethyl ketone (MEK) containing phosphoric acid, and then bathed in the ultrasound producer (KQ3200DE, $40 \mathrm{kHz}, 150 \mathrm{~W}$, China). Subsequently, the system was processed by heat hydrolysis, centrifugal separation, and vacuum concentration. Acetic acid was added into concentrated extraction in the volume ratio of one to three. And the formation of G-AA was promoted by using ultrasound producer (KQ3200DE, $40 \mathrm{kHz}, 150 \mathrm{~W}$, China) at room temperature. It followed that the solution was stored for $3 \mathrm{hr}$ in the dark to prevent photo-oxidation. Crude product was recovered by vacuum filter, washing with petroleum ether, and vacuum drying at room temperature for $12 \mathrm{hr}$. Finally, its weight was defined as the yield of sample.

To obtain of $99 \%$ pure G-AA, crude product was dissolved in acetone $(1: 10 \mathrm{w} / \mathrm{v})$, filtered through filter paper, and acetic acid with the volume ratio of one to three was added to induce crystallization. And then the solutions were treated in the ultrasound bath at room temperature for $2 \mathrm{~min}$. Pure G-
AA was recovered by the above-mentioned filtering, rinsing, drying technology.

\section{Process optimization}

Four important factors were optimized in the extraction and the crystallization steps (Figure 2). The optimization of the extraction conditions were restricted in the proper scope, such as phosphoric acid concentrations of $0.6,1.0,1.4,1.8$, or $2.0 \mathrm{~mol} / \mathrm{L}$, ultrasonic extracting times of $10,20,30,40$, or $50 \mathrm{~min}$, and refluxing times of $30,60,90,120$, or $150 \mathrm{~min}$, respectively. Ultrasound inducing time varying from 10 to $50 \mathrm{~min}$ was tested in the process of crystallization. To ensure the authenticity of the test, each experiment was repeated three times and relative deviation was controlled within $1.0 \%$, and final value is the general average of above parallel trials.

\section{Sample purity}

Preparation of Standard Curve. Firstly, $50 \mathrm{mg}$ of G-AA standard was weighed into a $100-\mathrm{mL}$ volumetric flask and filled to the mark with new distilled chloroform $\left(\mathrm{CDCl}_{3}\right)$ to achieve the $0.5 \mathrm{mg} / \mathrm{mL}(\mathrm{m} / \mathrm{v})$ standard solution for use. Secondly, a series volumes of above standard solutions, 50, 100, $150,200,250 \mu \mathrm{L}$, were transferred into 5-mL volumetric flasks, and respectively diluted to $5,10,15,20,25 \mu \mathrm{g} / \mathrm{mL}$ by the addition of the same chloroform. Thirdly, the diluted standard solutions were filled into quartz colorimetric cylinder and measured their absorbance at $365 \mathrm{~nm}$ in the UV equipment (Model Ultrospec 2100 pro, Biochrom, England) against the chloroform as the blank. According to the variation of absorbance (A) with the concentration (C) of standard solution, finally, the regression equation of standard curve was $A=-0.0201+0.03578 C(P<0.0001)\left(R^{2}=0.9989\right)$ by the software origin 7.0 (Microcal software).

Test of Sample Purity. The purity of crude gossypol products was determined by UV against a G-AA standard. The $15 \mu \mathrm{g} / \mathrm{mL}$ of crude product was prepared with the chloroform as described above. Its absorbance was determined at $365 \mathrm{~nm}$ against the blank solution. The ratio of its measured value to the predictive value base on standard curve was defined as the purity of sample.

Testing of the final G-AA product was conducted to ensure authenticity. The melting point was determined with a digital microscopical melting point apparatus (Model X-4, Beijing Tech Instrument, China). The UV/Vis spectrum was recorded in $\mathrm{CDCl}_{3}$ with a spectrophotometer (Ultrospec 2100 pro). The IR spectrum was recorded by potassium bromide tabletting with a spectrophotometer (Model EQUINX55, Bruker, Germany). To definite the accurate structure of product, the ${ }^{1} \mathrm{H}$ NMR was introduced by its solution in $\mathrm{CDCl}_{3}$ solvent with a Super-conducting Fourier Digital NMR spectrometer (Model AVANCF $300 \mathrm{MHz}$, Bruker, Switzerland).

\section{Antitumor activity assay}

Cell Culture and Reagents. Prostate cancer and breast cancer cell lines used were obtained from the American 
Type Culture Collection (Manassas, VA). Cells were routinely maintained in an improved Dulbecco's Modified Eagle's Medium (Biofluids, Rockville, MD) with $10 \%$ fetal bovine serum and $2 \mathrm{mmol} / \mathrm{L}$ L-glutamine. Cultures were maintained in a humidified incubator at $37^{\circ} \mathrm{C}$ and $5 \% \quad \mathrm{CO}_{2}$. G-AA was dissolved in dimethyl sulphoxide (DMSO) at $20 \mathrm{mmol} / \mathrm{L}$ as the stock solution.

Growth Inhibition Assay. Cell growth inhibition by GAA was determined by the methyl thiazolyl tetrazolium (MTT)-based assay using cell proliferation reagent watersoluble tetrazolium (WST-1) (Roche) according to the manufacturer's instruction. Briefly, cells (5000 cells/well) were plated in 96-well culture plates, and various concentrations of G-AA were added to the cells in triplicates. 4 days later, WST-1 was added to each well and incubated for $1.5 \mathrm{hr}$ at $37^{\circ} \mathrm{C}$. Absorbance was measured with a plate reader at 450 $\mathrm{nm}$ with correction at $650 \mathrm{~nm}$. The results are expressed as the $\%$ of absorbance of treated wells vs. that of vehicle control. $\mathrm{IC}_{50}$, the drug concentration giving $50 \%$ growth inhibition was calculated via sigmoid curve fitting using GraphPad Prism 5.0 (GraphPad).

Apoptosis Assay. PC-3 cells were incubated with G-AA sample or standard, and DMSO (control), for the $36 \mathrm{hr}$. At the end of treatment cells were washed in phosphate buffered solution (PBS) and analyzed for apoptosis. Morphology changes were observed by 4,6-diamino-2-phenylindole (DAPI) staining. After fixation with $70 \%$ ethanol for $15 \mathrm{~min}$, cells were incubated with DAPI in PBS for $15 \mathrm{~min}$. Cells were then washed with PBS for observation. Caspase-3 activities assay was performed by using Caspase-3 Assay Kit from BioVision following the manufacturer's instruction. Briefly, the cells were lysed in cell lysis buffer. The cell lysates were placed on ice for $10 \mathrm{~min}$ and centrifuged at $10,000 \mathrm{~g}$ for $5 \mathrm{~min}$.

Subsequently, caspase-3 activity was determined by N-acetyl-Asp-Glu-Val-Asp-pNA (Ac-DEVD-pNA), which is a substrate of caspase-3. After reaction of $2 \mathrm{hr}$ at $37^{\circ} \mathrm{C}$, the free pentose nucleic acid (pNA) was then quantified using a spectrophotometer at $405 \mathrm{~nm}$. Relative caspase-3 activity was evaluated by comparing the absolute absorbance from drugs treated cells with that of control.

Tumor cells were treated with G-AA at a series of concentrations, then trypsinized and washed with PBS, and fixed in $70 \%$ ethanol on ice. After centrifugation, cells were stained with $50 \mu \mathrm{g} / \mathrm{mL}$ propidium iodide and $0.1 \mu \mathrm{g} / \mathrm{mL}$ RNase A and analyzed by flow cytometry using a FACStar Plus cell sorter. Data were analyzed to calculate the percentage of sub-G1 population (apoptosis) using the CellQuest software (Becton Dickinson, Franklin).

\section{Results and Discussion}

\section{Effect of process conditions on the yield and content of $G-A A$}

Ultrasound Extracting Time. Currently, ultrasound assisted extraction has been widely utilized in chemical or medicine plants. Our ultrasound producer had invariable frequency of $40 \mathrm{kHz}$ and power of $150 \mathrm{~W}$; therefore, we mainly studied how ultrasonic extracting time affects on the mass and purity of the product. Different time was set varying

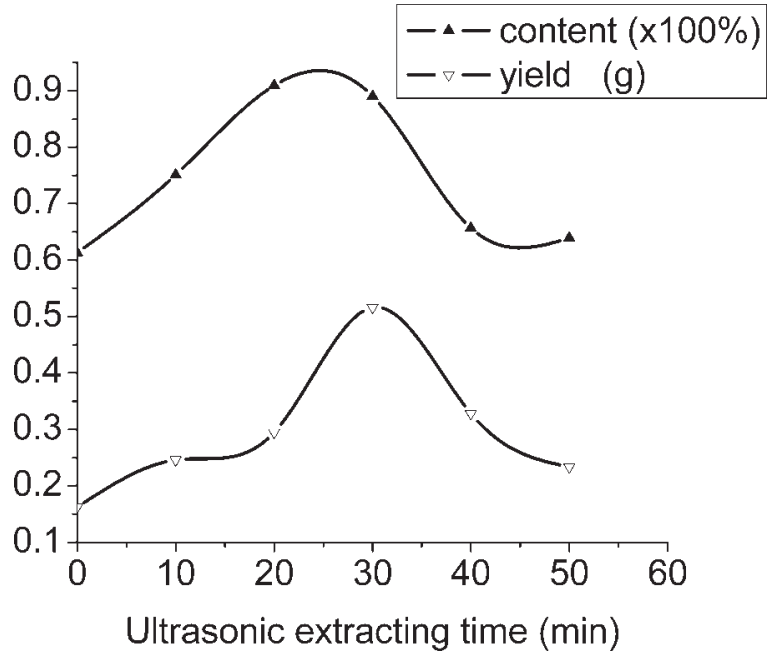

Figure 3. Effect of ultrasound extracting time on the content and yield of crude G-AA (acid concentration: $1.8 \mathrm{~mol} / \mathrm{L}$, refluxing time: $90 \mathrm{~min}$, sonocrystallization time: $\mathbf{3 0} \mathrm{min}$ ).

from 0 to $50 \mathrm{~min}$, and soapstock was treated as described in experimental section. It was shown in Figure 3 that time of ultrasonic treatment affected the quantity and quality of product significantly. The purity and yield of crude product was relatively low in the absence of ultrasound, and was increased distinctly in the presence of ultrasound. With the increase of ultrasonic extracting time, product yield and content appeared to reach a 'plateau' that represented the maximum. When the ultrasonic extracting time was beyond $30 \mathrm{~min}$, the content decreased slowly; however, the yield was evidently declined from $30 \mathrm{~min}(0.5164 \mathrm{~g})$ to $50 \mathrm{~min}(0.2337 \mathrm{~g})$.

It is well known that powerful ultrasound may make especial chemical effect in an individual reaction system. And the degree of the chemical effect could be examined with some methods such as KI dosimetry and Fricke dosimetry. ${ }^{27}$ The cavitation occurring in water yields hydroxyl radicals which lead to chemical decomposition, ${ }^{28,29}$ and the reduction in the yield could be attributed to the decomposition of GAA in too long process time. Further study will be conducted to examine the mechanism of ultrasonic degradation of $\mathrm{G}$ AA. The drop of sample purity might be attributed to substances mixed into G-AA during the continuous ultrasonic treatment.

Refluxing Time. To dissolve more gossypol into solvent, temperature is one of crucial factors in the hydrolysis of bound gossypol. It was obvious that the quality and quantity of crude G-AA changed with the hydrolysis time prolonging as shown in Figure 4. When the refluxing time was at 90 min, the content and yield of crude sample reached a peak. There was, however, a slight reduction in the yield of G-AA only when the refluxing time was beyond $90 \mathrm{~min}$ as the active aldehyde groups in the free gossypol tended to be turned into other inactive substance. Consequently, in view of the efficiency of hydrolytic reaction and the economy in energy, $90 \mathrm{~min}$ should be a reasonable refluxing time to ensure the stable quality of product.

Acid Concentration. It is well known that Schiff's complexes was formed between gossypol and phospholipids, or 


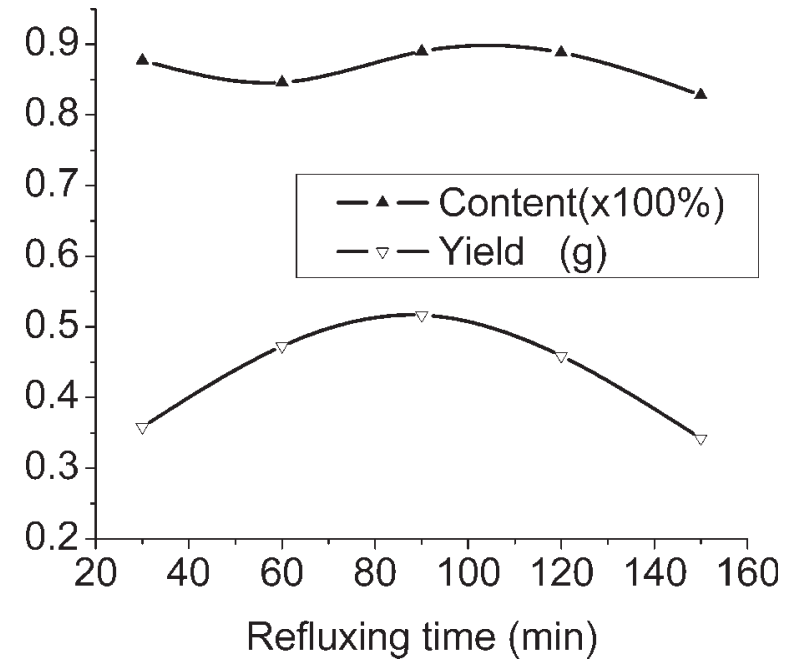

Figure 4. Effect of refluxing heating time on the content and yield of crude G-AA (ultrasonic extracting time: $30 \mathrm{~min}$, acid concentration: $1.8 \mathrm{~mol} / \mathrm{L}$, sonocrystallization time: $30 \mathrm{~min}$ ).

and peptide fragments, and any other amines in base conditions. Hence, gossypol with bound form is subsided in soapstock during alkali refining. However, gossypol could be released from its Schiff's complexes in acid conditions. In consideration of avoiding gossypol to be oxidized and retaining the intensity of acid hydrolysis, phosphoric acid was the better hydrolytic solvent than common acids including hydrochloric acid, sulfuric acid and nitric acid because of its high boiling point and low oxidization. As was it shown in Figure 5 , the content of G-AA in the crude sample has gradually increased until the top value is $89.0 \%$ at $1.8 \mathrm{~mol} / \mathrm{L}$ of acid concentration. Similarly, the yield of crude sample had a sharp increase and reached the peak at $1.6 \mathrm{~mol} / \mathrm{L}$. There was

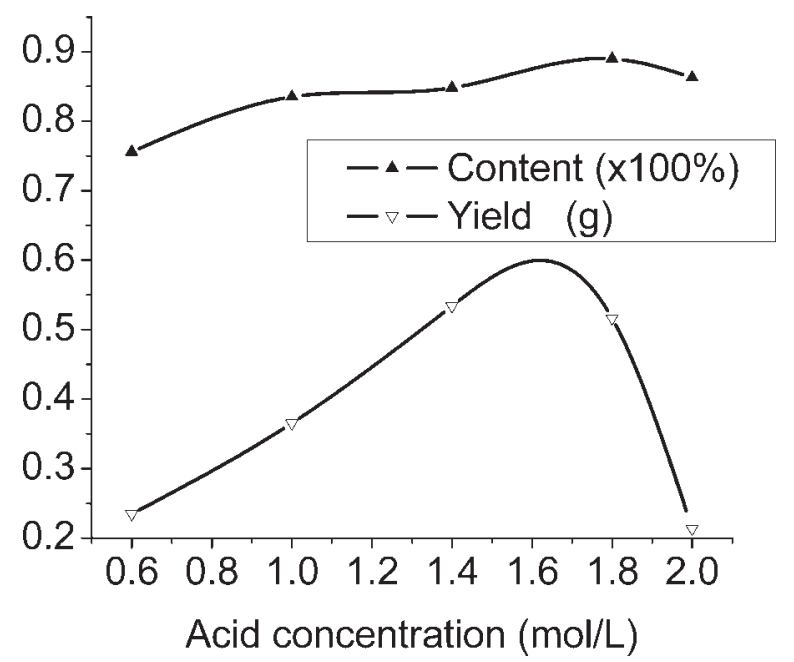

Figure 5. Effect of acid concentration on the content and yield of crude G-AA (ultrasonic extracting time: $30 \mathrm{~min}$, refluxing time: $90 \mathrm{~min}$, sonocrystallization time: $30 \mathrm{~min}$ ). a predominant decline in the quantity of G-AA, on the contrary, when acid concentration was beyond $1.8 \mathrm{~mol} / \mathrm{L}$. It was found that acid concentration had a notable influence on the content and yield of G-AA.

There are at least two main reasons for the changes of GAA with different acid concentrations. One and important reason is that the partial hydrolysis would lead to less free gossypol released in the organic solvent at the low concentration of acid. Secondly, the small quantity of crude products was possibly due to low saturation of the crystallization mother solution. It is difficult to vaporize further MEK at the same concentrated condition because the relative superfluous acid increased the boiling point of solution at the high acid concentration. It is clear that the acid concentration should be within range of $1.4 \mathrm{~mol} / \mathrm{L}$ and $1.8 \mathrm{~mol} / \mathrm{L}$.

Time of Ultrasonic Crystallization. Currently, rapid sonocrystallization, an undeveloped process in crystallization field, was investigated in the recent studies. ${ }^{30,31}$ With its intensive vibration, cavitation and transmission, ultrasound can uniformly blend the solutions on the microscopic scale, and hasten mass transfer of the insonated crystal products. Consequently, it was by changing the ultrasonic power, duration, and the volume of mixture that the mean size, size distribution and shape of crystal could be controlled efficiently. ${ }^{30}$

To study the sonication effect on the recovery of G-AA, we adjusted sonocrystallization time in range of $0-50 \mathrm{~min}$. The yield and content of G-AA had similar tend as ultrasonic inducing time prolonged as shown in Figure 6. The recovery of G-AA increased and reached peak when ultrasonic time was $30 \mathrm{~min}$. After that, content of G-AA declined gradually because of the coprecipitation of some foreign materials. The decomposition of G-AA in long ultrasound crystallizing time also possibly led to the decline in yield of crude products. It was obvious that the recovery of G-AA was greatly different between ultrasonic process and nonultrasoinc process. And we noticed that the crystal of G-AA began to form at least $24 \mathrm{hr}$ later in the conventional standing crystallization

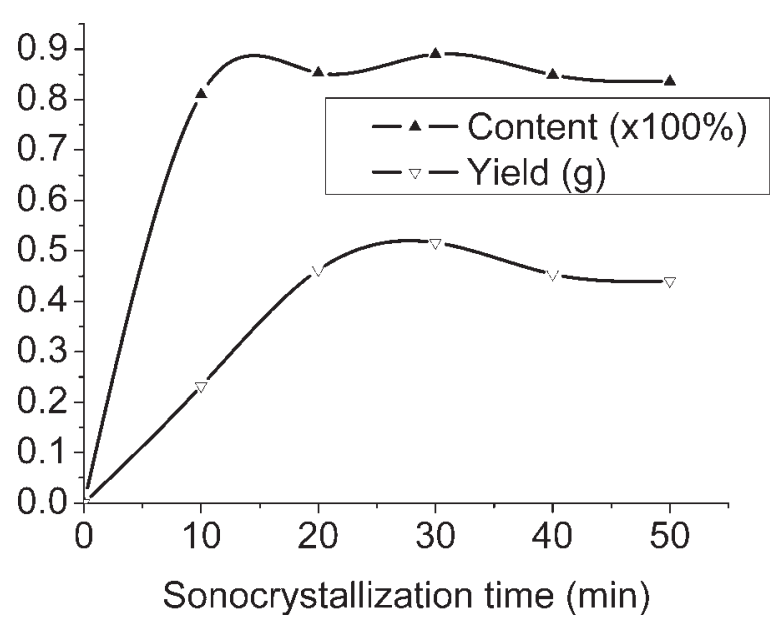

Figure 6. Effect of the induction time on the content and yield of crude G-AA (ultrasonic extracting time: $\mathbf{3 0} \mathrm{min}$, acid concentration: $1.8 \mathrm{~mol} /$ $L$, refluxing time: $90 \mathrm{~min}$ ). 
Table 1. Optimized Experiment Data of G-AA Extracted From Cottonseed Soapstock by Ultrasound $\mathrm{L}_{9}\left(3^{4}\right)$

\begin{tabular}{|c|c|c|c|c|}
\hline \multirow[b]{2}{*}{ Essay No. } & \multicolumn{3}{|c|}{ Factors } & \multirow{2}{*}{$\begin{array}{c}\text { Recovery Value } \\
\text { Mass of } \\
\text { Pure } \\
\text { G-AA (mg) }\end{array}$} \\
\hline & $\mathrm{A}(\mathrm{min})$ & $\mathrm{B}(\mathrm{mol} / \mathrm{L})$ & $\mathrm{C}(\min )$ & \\
\hline 1 & $1(20)$ & $1(1.4)$ & $1(20)$ & 455 \\
\hline 2 & 1 & $2(1.6)$ & $2(25)$ & 671 \\
\hline 3 & 1 & $3(1.8)$ & $3(30)$ & 268 \\
\hline 4 & $2(25)$ & 2 & 3 & 759 \\
\hline 5 & 2 & 3 & 1 & 831 \\
\hline 6 & 2 & 1 & 2 & 1243 \\
\hline 7 & $3(30)$ & 3 & 2 & 672 \\
\hline 8 & 3 & 1 & 3 & 453 \\
\hline 9 & 3 & 2 & 1 & 358 \\
\hline$K_{1}$ & 1394 & 2151 & 1644 & \\
\hline$K_{2}$ & 2833 & 1788 & 2586 & \\
\hline$K_{3}$ & 1483 & 1771 & 1480 & \\
\hline $\mathrm{K}_{1}$ & 465 & 717 & 548 & \\
\hline $\mathrm{K}_{2}$ & 944 & 596 & 862 & \\
\hline $\mathrm{K}_{3}$ & 494 & 590 & 493 & \\
\hline $\mathrm{R}$ & 480 & 127 & 369 & \\
\hline $\begin{array}{l}\text { Optimized } \\
\text { combination }\end{array}$ & $A_{2}$ & $B_{1}$ & $C_{2}$ & \\
\hline
\end{tabular}

A, ultrasound extracting time; B, acid concentration; C, sonocrystallization time.

$K_{1}, K_{2}, K_{3}$, Sum of recovery values of same level in a factor.

$K_{1}, K_{2}, K_{3}$, Mean of recovery values of same level in a factor.

$\mathrm{R}$ (range), Difference of maximum and minimum among $\mathrm{k}_{\mathrm{i}}$ in a factor.

described by Dowd et al. ${ }^{18}$ So, powerful ultrasound is an advanced way to prompt crystallization during the preparation of G-AA up to the present.

Because of its inducing initial nucleation in nominally particle-free solutions at much lower supersaturation levels, ultrasound can speed up crystallization. The application of ultrasound to a liquid induces the phenomenon of cavitation in the process fluid. It is possible that cavitation plays an important role in the increase of nucleation rate which results in higher G-AA recovery in sonicated samples. The effect of cavitation to speed up the nucleation rate is a complex phenomenon and has not yet been fully explained. ${ }^{25}$ Some believed that subsequent rapid local cooling rates, calculated at $10^{7}-10^{10} \mathrm{~K} / \mathrm{s}$, played a significant part in increasing supersaturation; others argued that the increases in localized pressure decreased the crystallization temperature; still others insisted that the cavitation events allow the excitation energy barriers related with nucleation to be surmounted.

It can also be speculated that the local solvent evaporation takes place within the cavitation nuclei due to hot spot for- mation as a result of cavity collapse. ${ }^{31}$ On collapse of a cavity, these nuclei are introduced into the crystallization slurry and caused further cavitational opportunities due to the presence of these solids. ${ }^{32}$ In the absence of sonication samples, however, the rate of crystallization appears to be rather less, possibly due to comparatively slow mixing and nucleation.

As shown in Figure 6, the continuous ultrasonic seldom contributes to the crystallization of G-AA beyond $30 \mathrm{~min}$. To shorten the cycle of crystallization and reduce the consumption of energy, consequently, the range of ultrasonic inducing time was chosen as 20-30 min.

\section{Optimization of ultrasound extracting conditions of $G-A A$ from cottonseed soapstock}

The effects of ultrasonic extracting time, refluxing time, acid concentration, and ultrasound crystallizing time on the recovery of G-AA from cottonseed soapstock were analyzed. It was reasonable that refluxing time was $90 \mathrm{~min}$ for the stable quality of product. In view of the principle of homogenous design, the extracting conditions were respectively limited in the proper scopes, that is, 20-30 min of ultrasonic extracting time (A), $1.4-1.8 \mathrm{~mol} / \mathrm{L}$ of acid concentration (B), and $20-30 \mathrm{~min}$ of ultrasound crystallizing time $(\mathrm{C})$. On the basis of the uniform combination among three factors and three levels, nine experimental points were shown in Table 1.

Nine experiments were carried out according to uniformly combinatorial conditions, and mass of pure G-AA is the multiplication result of the content of G-AA and the yield of every crude product as the final result. These results were then analyzed by DPS (Data Process System, made in Zhejiang University, China) and the analysis of their range and variance were shown in Table 1 and 2. It was found that ultrasound extracting time (A) and ultrasound crystallizing time (C) affected the recovery of G-AA significantly $(P<0.01)$. No.6 was chosen as the optimized experimental conditions $\left(\mathrm{A}_{2} \mathrm{~B}_{1} \mathrm{C}_{2}\right)$ for its high recovery of G-AA. In other words, $1243 \mathrm{mg}$ of pure G-AA coming from $1296 \mathrm{mg}$ and $95.9 \%$ crude product was prepared when ultrasonic extracting time, acid concentration, and ultrasound crystallizing time were respectively settled at $25 \mathrm{~min}, 1.4 \mathrm{~mol} / \mathrm{L}$, and $25 \mathrm{~min}$.

\section{Characterization of the product}

To definite clearly the purity of G-AA, melting point test and spectrum scan were used in this study. G-AA sample from the recrystallization in acetone solvent was tested with a digital microscopical melting point apparatus. The melting

Table 2. Analysis of Variance About the Data in the Optimization Experiment

\begin{tabular}{|c|c|c|c|c|c|}
\hline Source of Variation & $\begin{array}{l}\text { Sum of } \\
\text { Squares }\end{array}$ & $\begin{array}{c}\text { Degrees of } \\
\text { Freedom }\end{array}$ & $\begin{array}{c}\text { Mean } \\
\text { Square }\end{array}$ & $F$-value & $P$ \\
\hline $\mathrm{A}(\min )$ & 433,460 & 2 & 216,730 & 313.45 & $0.00318(* *)$ \\
\hline $\mathrm{B}(\mathrm{mol} / \mathrm{L})$ & 30,718 & 2 & 15,359 & 22.21 & $0.04308(*)$ \\
\hline $\mathrm{C}(\min )$ & 237,500 & 2 & 118,750 & 171.74 & $0.00579(* *)$ \\
\hline Error & 1383 & 2 & 691 & & \\
\hline Total & 703,060 & 8 & & & \\
\hline
\end{tabular}

The result of analysis of variance was obtained by F-test method.

A, ultrasound extracting time; $\mathrm{B}$, acid concentration; $\mathrm{C}$, sonocrystallization time.

*Significant $(P<0.05)$; **Very significant $(P<0.01)$. 


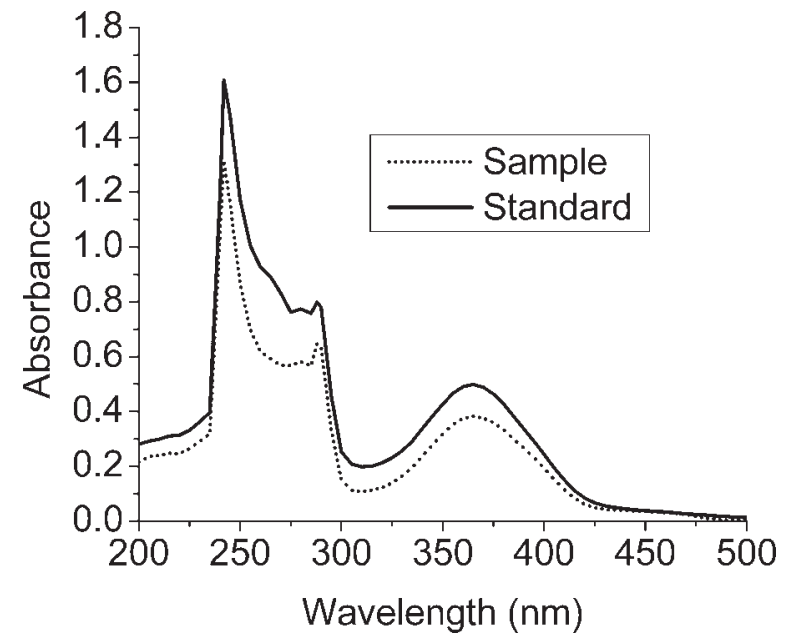

Figure 7. UV scan spectrum of G-AA in $\mathrm{CDCl}_{3}$ (sample and standard concentrations are $12 \mu \mathrm{g} / \mathrm{mL}$ and $15 \mu \mathrm{g} / \mathrm{mL}$ respectively).

point of the material was $181-182^{\circ} \mathrm{C}$ in reasonable agreement with values reported by Clark, ${ }^{33}$ Campbell et al., ${ }^{34}$ and Murty et al., ${ }^{35}$ which ranged between 180 and $187^{\circ} \mathrm{C}$. It was shown that there are a few crystal styles in our product.

UV-Vis spectrum analysis, as a fast method, is used to determine the structure of material according to the special absorbance of its functional group. The UV-Vis spectrum
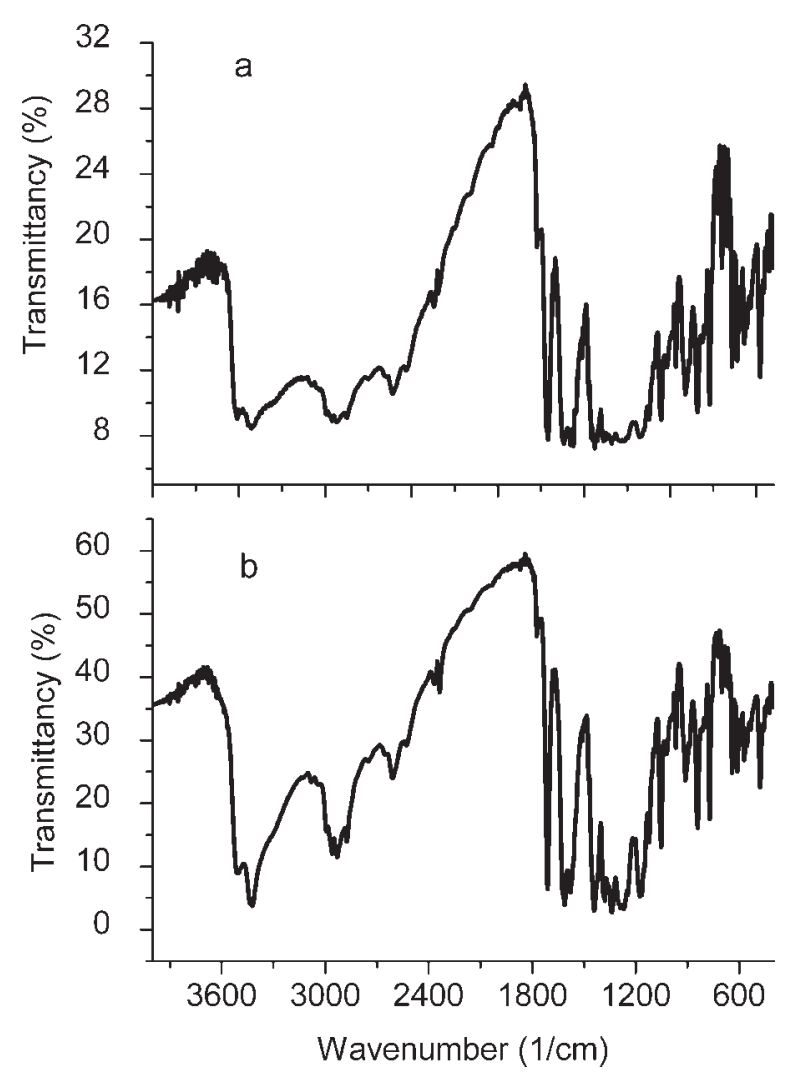

Figure 8. ${ }^{1} \mathrm{H}$ NMR of G-AA in $\mathrm{CDCl}_{3}$ (a. Standard; $b$. Sample).
(Figure 7) of our product in chloroform (peaks: 243, 278, 289, and $365 \mathrm{~nm}$ ) was identical to the spectrum reported by Dowd et al.. ${ }^{18}$ Therefore, we picked out the wavelength of maximum absorbent peak at $365 \mathrm{~nm}$ as the special absorbance of free aldehyde group, and the absorbance of all products were recorded for calculating the content of G-AA in crude materials.

IR spectrum is able to reveal directly the detail information of structure of chemical material. We got the IR scan result of G-AA shown in Figure 8 by the $\mathrm{KBr}$ pellet method. There are similar spectra between the sample (Figure 8a) and standard (Figure 8b) of G-AA and significant functional groups are markedly shown. The maximum absorption peaks around $3400 \mathrm{~cm}^{-1}$ illustrated the region of the $v(\mathrm{O}-\mathrm{H})$ vibrations of sample $\left(3427 \mathrm{~cm}^{-1}\right)$ and standard preparation $\left(3425 \mathrm{~cm}^{-1}\right)$. The peaks at $1710 \mathrm{~cm}^{-1}$ (a) and $1708 \mathrm{~cm}^{-1}$ (b) assigned to the $v(\mathrm{C}=\mathrm{O})$ vibration in aldehyde, ketone, or carboxylic acid. However, a serials of peaks nearby 3000 $\mathrm{cm}^{-1}$ meant the $v(\mathrm{O}-\mathrm{H})$ vibration of carboxylic acid, and the bands appeared at $2610 \mathrm{~cm}^{-1}$ (a) and $2608 \mathrm{~cm}^{-1}$ (b) meant the vibration of bond between carbon and hydrogen, which demonstrated the existence of aldehyde group. This spectral feature at $1615 \mathrm{~cm}^{-1}$ and $1577 \mathrm{~cm}^{-1}$ revealed $v(\mathrm{C}=\mathrm{C})$ vibration in aromatic ring, and the $v(\mathrm{C}-\mathrm{O})$ vibration in naphthol was shown at $1269 \mathrm{~cm}^{-1}$ in Figure 8.

The ${ }^{1} \mathrm{H}$ NMR spectra of G-AA were recorded in $\mathrm{CDCl}_{3}$ using a spectrometer (AVANCF, $300 \mathrm{MHz}$ ). As shown in Figure 9, there was the similar response signal between standard and sample of G-AA, which illustrated that they could be the same compound. The ${ }^{1} \mathrm{H}$ NMR data for standard and sample of G-AA were summarized in Tables 3. Therefore, the ${ }^{1} \mathrm{H}$ NMR spectrum further ensured the high purity of our product.
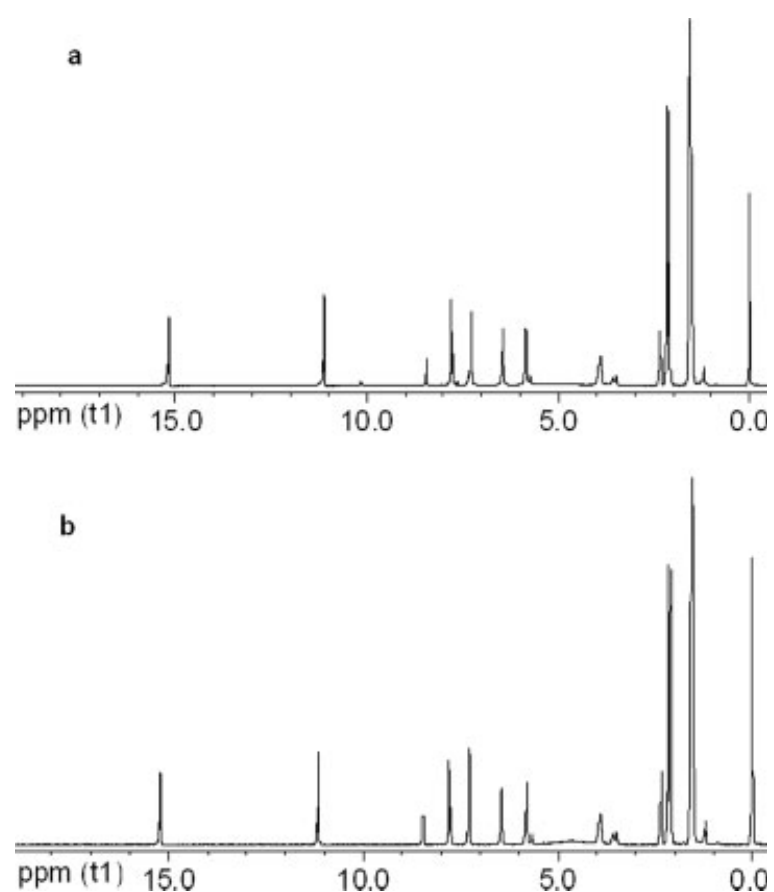

Figure 9. IR scan spectrum (a. Sample; b. Standard). 
Table 3. ${ }^{1} \mathrm{H}$ NMR Chemical Shifts (ppm) for the G-AA in the $\mathrm{CDCl}_{3}$

\begin{tabular}{|c|c|c|c|c|c|c|c|c|c|c|}
\hline \multirow[b]{2}{*}{ Compound } & \multicolumn{10}{|c|}{ Chemical shift (ppm) } \\
\hline & $\begin{array}{l}11\left(11^{\prime}\right)- \\
\mathrm{C}\left(\mathrm{CH}_{3}\right)_{2} \\
\end{array}$ & $\begin{array}{c}14\left(14^{\prime}\right)- \\
\mathrm{CH}_{3} \\
\end{array}$ & $\begin{array}{c}13\left(13^{\prime}\right)- \\
\mathrm{CH}_{3}\end{array}$ & $\begin{array}{c}11\left(11^{\prime}\right)- \\
\mathrm{CH}\end{array}$ & $\begin{array}{l}1\left(1^{\prime}\right)- \\
\mathrm{C}-\mathrm{OH}\end{array}$ & $\begin{array}{l}6\left(6^{\prime}\right)- \\
\mathrm{C}-\mathrm{OH} \\
\end{array}$ & $\begin{array}{l}4\left(4^{\prime}\right)- \\
\mathrm{C}-\mathrm{H}\end{array}$ & $\begin{array}{c}17- \\
\mathrm{COOH}\end{array}$ & $\begin{array}{c}15\left(15^{\prime}\right)- \\
\mathrm{CHO}\end{array}$ & $\begin{array}{l}7\left(7^{\prime}\right)- \\
\mathrm{C}-\mathrm{OH} \\
\end{array}$ \\
\hline Standard & $1.56(\mathrm{~d})$ & $2.13(\mathrm{~s})$ & $2.34(\mathrm{~s})$ & $3.58(\mathrm{~m})$ & $5.79(\mathrm{~s})$ & $6.44(\mathrm{~s})$ & $7.73(\mathrm{~s})$ & $8.45(\mathrm{~s})$ & $11.15(\mathrm{~s})$ & $15.21(\mathrm{~s})$ \\
\hline Sample & $1.56(\mathrm{~d})$ & $2.13(\mathrm{~s})$ & $2.34(\mathrm{~s})$ & $3.57(\mathrm{~m})$ & $5.73(\mathrm{~s})$ & $6.44(\mathrm{~s})$ & $7.76(\mathrm{~s})$ & $8.46(\mathrm{~s})$ & $11.15(\mathrm{~s})$ & $15.22(\mathrm{~s})$ \\
\hline
\end{tabular}

s, singlet; d, doublet; m, multiplet.

\section{Antitumor activity}

To test the tumor inhibition effect of G-AA prepared by the ultrasound extraction and crystallization, MTT-based cell growth assay was carried out as described method ${ }^{14}$ in experimental section. According to the results in Figure 10, the values of $\mathrm{IC}_{50}$ of G-AA sample were similar to G-AA standard in both human prostate cancer cell line PC-3 (Figure 10a) and human breast cancer cell line MDA-MB-231 (Figure 10b), which implied that our product had similar biological activity as standard. The ultrasound assisted extraction and crystallization technology sped up the process
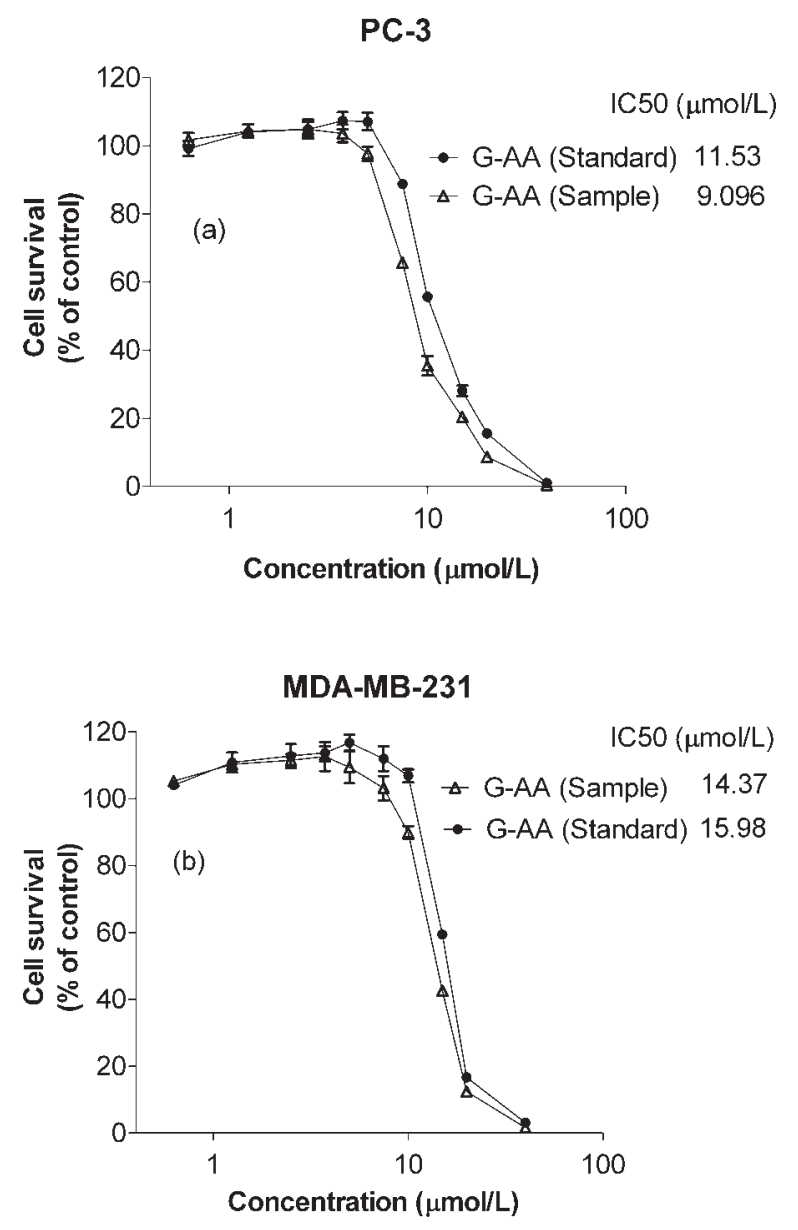

Figure 10. Inhibiting effect of G-AA on tumor cells (a. prostate cancer cell line PC-3 was inhibited by different concentration G-AA; b. human breast cancer cell line MDA-MB-231 by different concentration G-AA). of recovery for G-AA, and was able to avoid the degeneration of G-AA as result of little chance for touch with air.

Caspase-3 activation plays a pivotal role in apoptosis and also serves as a critical indicator for apoptosis. As shown in Figure 11, both G-AA sample and G-AA standard at the concentrations of 10 and $20 \mu \mathrm{mol} / \mathrm{L}$ induced similar caspase-3 activation and in a dose-dependent manner, indicating that both of the compounds had similar apoptosis inducing effect.

Karyorrhexis is a typical morphologic change of apoptosis cells, which means the nuclei broken down into pieces. DAPI is a dye specifically stains the cell nuclei. As shown in Figure 12, after $36 \mathrm{hr}$ incubation with $20 \mu \mathrm{mol} / \mathrm{L}$ G-AA sample or standard, apoptotic PC-3 cells were observed in both treatments.

Low content (less 1\%) materials including cottonseed, cottonseed oil, and the root bark of the cotton were utilized in the conventional process of recovering gossypol, which led to high cost of G-AA. In compared, soapstock with high content $(2 \%)$ gossypol, an industrial waste in some oil refine plants, was developed in our process, which further decreased the cost of G-AA. Down et al. obtained the 8792.2\% pure G-AA product in $16 \mathrm{hr}$ according to their conventional process and didn't show whether their product could inhibit the growth of tumor. After the ultrasound assisted extraction and crystallization technology was introduced in this novel process; we could achieve the initial product with $95.9 \%$ pure G-AA only in about $4 \mathrm{hr}$. Moreover, high content initial product would relieve the pressure from the recrystallization (standard grade G-AA was obtained by ultrasound recrystallizing in $2 \mathrm{~min}$ ). It is notable that our product shown the similar biological activity to the standard in both the growth inhibition and apoptosis induction in prostate cancer cell line PC-3 and human breast cancer cell line

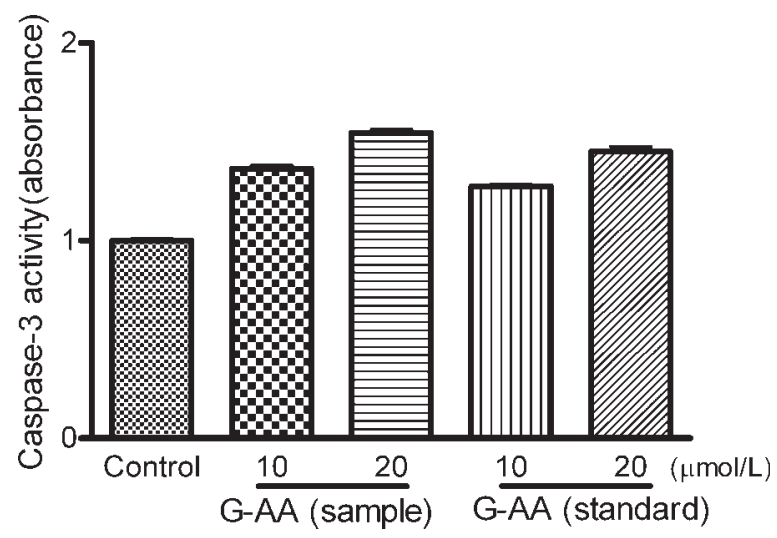

Figure 11. Caspase-3 activity assay.

March 2009 Vol. 55, No. 3

AIChE Journal 


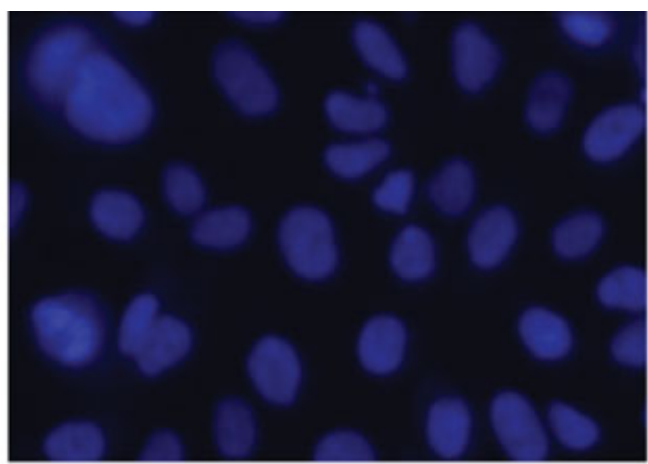

(a) Control

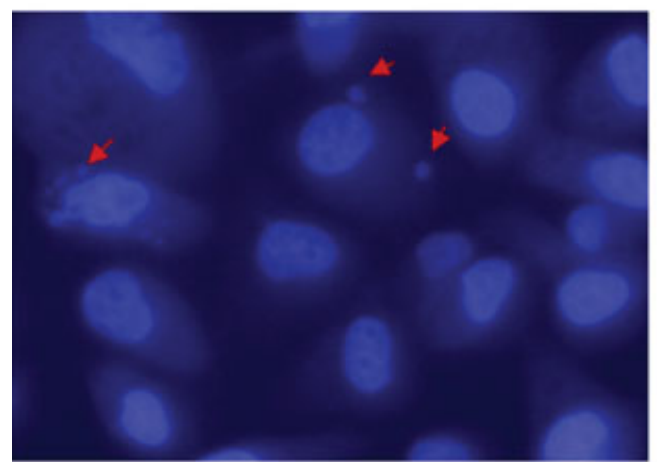

(b) G-AA 20 umol/L (Sample)

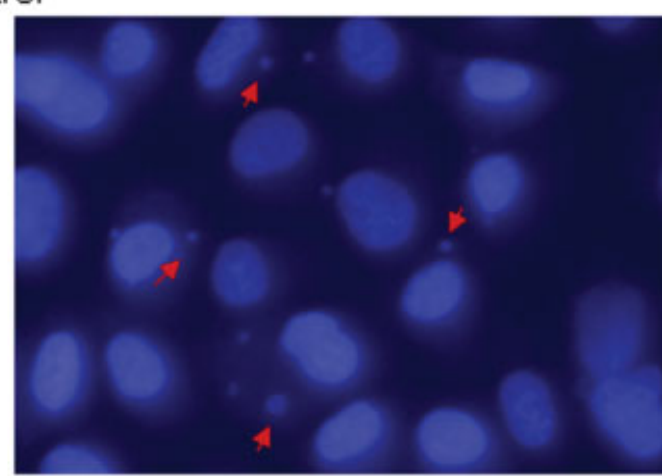

(c) G-AA 20 umol/L (Standard)

Figure 12. Apoptotic morphology changes caused by G-AA (400×).

[Color figure can be viewed in the online issue, which is available at www.interscience.wiley.com.]

MDA-MB-231. Therefore, with the further research about antitumor effect of gossypol and its derivates which we succeed in synthesizing (Data was not shown), it is promising that this novel process offers abundant, low-cost, high pure and bioactive gossypol for treating cancer.

\section{Conclusions}

The novel process in our study can make good use of industrial waste and decrease the cost of G-AA. Ultrasound extraction and crystallization technology introduced in this novel process shortened product cycle, retained the antitumor activity of gossypol and boosted the quality of product. It is promising that large scale of G-AA with high antitumor activity is extracted from cottonseed soapstock by our novel ultrasound assisted method.

\section{Acknowledgments}

The authors thank Shannxi Shiyang Oil and Feed Co. Ltd. for the soapstock samples, Dr. Jian-jun Li for the material preparation, Na Guo for the gossypol purification. This study was supported in part by grants from National Natural Science Foundations of China (Nos. 30570494, 30772658, and 30710403089) (to D. Wu) and USA Department of Defense Prostate Cancer Research Program W81XWH-04-1-0215 and W81XWH-06-1-0010 (to L. Xu). Recently, our study was supported by grants from Shaanxi Provincial Department of Education Science Research Program 08JK218 and Shaanxi Institute of Education Science Research Program 09KJ07 in China (to G. Jia).

\section{Literature Cited}

1. Coutinho EM. Gossypol: a contraceptive for men. Contraception. 2002;65:259-263.

2. Razakantoanina V, Phung NKP, Jaureguiberry G. Antimalrial activity of new gossypol derivatives. Parasitol Res. 2000;86:665-668.

3. Bushunow P, Reidenberg MM, Wasenko J, Winfield J, Lorenzo B, Lemke S, Himpler B, Corona R, Coyle T. Gossypol treatment of recurrent adult malignant gliomas. J Neurooncol. 1999;43:79-86.

4. Keller PA, Birch C, Leach SP, Tyssen D, Griffith R. Novel pharmacophore-based methods reveal gossypol as a reverse transcriptase inhibitor. J Mol Graph. 2003;21:365-373.

5. Zhang JF, Cao CH, Yuan T, Gui YP. Gossypol acetate induces apoptosis in human T24 urinary bladder cancer cells. J Tongji Med Univ. 2002;24:18-19, 30.

6. Van Poznak C, Seidman AD, Reidenberg MM, Moasser MM, Sklarin N, Van Zee K, Borgen P, Gollub M, Bacotti D, Yao TJ, Bloch R, Ligueros M, Sonenberg M, Norton L, Hudis C. Oral gossypol in the treatment of patients with refractory metastatic breast cancer: a phase I/ II clinical trial. Breast Cancer Res Tr. 2001;66:239-248.

7. Xu L, Yang D, Wang S, Liu M, Chen J, Lawrence T, Lippman ME. Radiosensitization of human prostate cancer by natural polyphenol inhibitor of Bcl-2/XL, (-)-gossypol, results in tumor regression. Eur J Cancer Suppl. 2004;2:94.

8. Zhang MC, Liu HP, Tian ZK, Griffith BN, Ji M, Li QQ. Gossypol induces apoptosis in human PC-3 prostate cancer cells by modulating caspase-dependent and caspase-independent cell death pathways. Life Sci. 2007;80:767-774.

9. Geldof A, Kuipers G, Sminia P, Lafleur M, Zerp S, Yang D, Lippman M, Slotman B, Verheif M. Gossypol, a small molecule inhibitor of BCL-2, increases radiation-induced cytotoxicity in human prostate and head and neck cancer cells. Radiother Oncol. 2006;78(Suppl 1):S83. 
10. Wu YW, Chik CL, Knazek RA. An in vitro and in vivo study of antitumor effects of gossypol on human SW-13 adrenocortical carcinoma. Cancer Res. 1989;49:3754-3758.

11. Flack MR, Pyle RG, Sullen NM, Lorenzo B, Wu Y, Knazek RA, Nisula BC, Reidenberg AM. Oral gossypol in the treatment of metastatic adrenal cancer. J Clin Endocrinol Metab. 1993;76:1019-1024.

12. Benz CC, Keniry MA, Ford JM, Townsend AJ, Cox FW, Palayoor S, Matlin SA, Hait WN, Cowan KH. Biochemical correlates of the antitumor and antimitochondrial properties of gossypol enantimers. Mol Pharmacol. 1990;37:840-847.

13. Oliver CL, Miranda MB, Shangary S, Land S, Wang S, Johnson DE. (-)-Gossypol acts directly on the mitochondria to overcome Bcl2- and Bcl-XL-mediated apoptosis resistance. Mol Cancer Ther. 2005;4:23-31.

14. Xu L, Yang D, Wang S, Tang W, Liu M, Davis M, Chen J, Rae JM, Lawrence T, Lippman ME. (-)-Gossypol enhances response to radiation therapy and results in tumor regression of human prostate cancer. Mol Cancer Ther. 2005;4:197-205.

15. Carruth FE. Contribution to the chemistry of gossypol, the toxic principle of cottonseed. J Am Chem Soc. 1918;40:647-663.

16. Royce HD, Harrison JR, Hahn ER. Cotton-root bark as a source of gossypol. J Am Oil Chem Soc. 1941;18:27-29.

17. Castillon LE, Hall CM, Boatner CH. Preparation of gossypol from cottonseed pigment glands. J Am Oil Chem Soc. 1948;25:233236.

18. Dowd MK, Pelitire SM. Recovery of gossypol acetic acid from cottonseed soapstock. Ind Crop Prod. 2001;14:113-123.

19. Chen F, Sun Y, Zhao G, Liao X, Hu X, Wu J, Wang Z. Optimization of ultrasound-assisted extraction of anthocyanins in red raspberries and identification of anthocyanins in extract using high-performance liquid chromatography-mass spectrometry. Ultrason Sonochem. 2007; 14:767-778.

20. Hromadkova Z, Ebringerova A, Valachovic P. Ultrasound-assisted extraction of water-soluble polysaccharides from the roots of valerian (Valeriana officinalis L.). Ultrason Sonochem. 2002;9:37-44.

21. Rodrigues S, Pinto GAS, Fernandes FAN. Optimization of ultrasound extraction of phenolic compounds from coconut (Cocos nucifera) shell powder by response surface methodology. Ultrason Sonochem. 2007;15:95-100.
22. Amara N, Ratsimba B. Crystallization of potash alum: effect of power ultrasound. Ultrason Sonochem. 2001;8:265.

23. McCausland LJ, Cains PW, Martin PD. Use the power of sonocrystallization for improved properties. Chem Eng Prog. 2001;97:5661.

24. Dalas E. The effect of ultrasonic field on calcium carbonate scale formation. J Crys Grow. 2001;222:287-292.

25. Ruecroft G, Hipkiss D, Ly T, Maxted N, Cains PW. The use of ultrasound for improved industrial crystallization. Org Process Res Dev. 2005;9:923-932.

26. AOCS. Ba 8-78 Total Gossypol in Official Methods and Recommended Practices of the AOCS, 5th ed. Am Oil Chem Soc: Champaign, IL, 1998.

27. Koda S, Kimura T, Kondo T, Mitome H. A standard method to calibrate sonochemical efficiency of an individual reaction system. Ultrason Sonochem. 2003;10:149-156.

28. Castellanos MM, Reyman D, Sieiro C, Calle P. ESR-spin trapping study on the sonochemistry of liquids in the presence of oxygen. Evidence for the superoxide radical anion formation. Ultrason Sonochem. 2001;8:17-22.

29. Vercet A, Lopez P, Burgos J. Free radical production by manothermosonication. Ultrasonics. 1998;36:615-618.

30. Li H, Wang J, Bao Y, Guo Z, Zhang M. Rapid sonocrystallization in the salting-out process. J Crys Grow. 2003;247:192-198.

31. Bund RK, Pandit AB. Sonocrystallization: effect on lactose recovery and crystal habit. Ultrason Sonochem. 2007;14:143-152.

32. Gogate PR, Mujumdar S, Pandit AB. Sonochemical reactors for waste water treatment: comparison using formic acid degradation as a model reaction. Adv Environ Res. 2003;7:283-299.

33. Clark EP. Studies on gossypol. I. The preparation, purification, and some of the properties of gossypol, the toxic principle of cottonseed. J Biol Chem. 1927;75:725-739.

34. Campbell KN, Morris RC, Adams R. The structure of gossypol I. J Am Chem Soc. 1937;59:1723-1728

35. Murty VK, Murty KS, Seshadri TR. Chemistry of gossypol. Part I. Preparation and properties. Proc. Indian Acad Sci. 1942;A16:54 61.

Manuscript received Apr. 25, 2008, and revision received Aug. 8, 2008. 